\title{
Supporting Information: Achieving and Stabilizing Uranyl Bending via Physical Pressure
}

Eike M. Langer†, Philip Kegler†, Piotr M. Kowalski†, Shuao Wang,§ and Evgeny V. Alekseev†,*

$\dagger$ Institute of Energy and Climate Research, Forschungszentrum Jülich GmbH, D-52428, Jülich, Germany

$\S$ State Key Laboratory of Radiation Medicine and Protection, School for Radiological and Interdisciplinary Sci-ences (RAD-X) and Collaborative Innovation Center of Radiation Medicine of Jiangsu Higher Education Institu-tions, Soochow University, Suzhou 215123, China 


\section{Experimental Procedure:}

\section{Synthes is}

Caution! As uranium dioxide, used in this study, contains a-emitting depleted uranium, standard precautions need to be considered for such materials. All studies were conducted in a laboratory dedicated to studies on radioactive elements.

$\mathrm{UO}_{2}, \mathrm{SeO}_{2}$, and $\mathrm{NaS}_{2} \mathrm{O}_{3}$ were used as received and a finely ground mixture with a molar ratio of 1:5:2 for U:Se:S was filled within a platinum crucible and sealed using an impulse micro welding device (Lampert PUK U4). The high-temperature/high-pressure experiment was performed utilizing the piston cylinder module of a Voggenreiter LP 1000-540/50 at Forschungszentrum Jülich, IEK-6 in a $1 / 2$ inch piston cylinder talc-pyrex assembly. The synthesis was performed at a pressure of $3.5 \mathrm{GPa}$, applied prior to heating and released post quenching. The capsule with the reaction mixture was heated to $1000^{\circ} \mathrm{C}$ with a heating rate of $100^{\circ} \mathrm{C} / \mathrm{min}$, held at the temperature for 12 hours and subsequently cooled in two steps to $200^{\circ} \mathrm{C}$ finishing off by a quench. The cooling rate for the first step to $433^{\circ} \mathrm{C}$ was $100^{\circ} \mathrm{C} / \mathrm{h}$ and for the second step to $200^{\circ} \mathrm{C}$ was $10^{\circ} \mathrm{C} / \mathrm{h}$. The calibration procedure of the piston cylinder module is described in detail in the Supporting Information of 18.

The resulting light green crystals of $\mathrm{Na}_{4}\left[\left(\mathrm{UO}_{2}\right)\left(\mathrm{SO}_{4}\right)_{3}\right]$ were found together with a easily shearing unstable crystalline yellow phase (ratio roughly 1:10). Upon opening of the crucible, water was taken up by the sample from ambient air, resulting in a gel-like formation - the $\mathrm{Na}_{4}\left[\left(\mathrm{UO}_{2}\right)\left(\mathrm{SO}_{4}\right)_{3}\right]$ however remained stable.

\section{Crystallographic Studies}

The as-obtained $\mathrm{Na}_{4}\left[\left(\mathrm{UO}_{2}\right)\left(\mathrm{SO}_{4}\right)_{3}\right]$ crystals were selected for data collection. The crystals were mounted on glass fibers and optically aligned on an Agilent single crystal diffractometer (SuperNova, Dual Source). Data collection was done using mono-chromatic Mo-K $\alpha$ radiation with an incident wavelength of $0.71073 \AA$, with the X-ray tube operated at $50 \mathrm{kV}$ and $0.8 \mathrm{~mA}$ providing a beam size of approximately $30 \mu \mathrm{m}$. The unit-cell dimensions for the title phase were refined using least-squares techniques against the positions of all measured reflections. More than a hemisphere of data were collected for each crystal and the three-dimensional data were reduced and filtered for statistical outliers using the machine-standard CrysAlisPro software. Data were corrected for Lorentz, polarization, absorption and background effects. The structure was solved by direct methods and refined to an optimum $\mathrm{R}_{1}=0.0538$ value with SHELXL ${ }^{1}$ operated within the WinGX v2014.1 program suite ${ }^{2}$. The crystallographic information for $\mathrm{Na}_{4}\left[\left(\mathrm{UO}_{2}\right)\left(\mathrm{SO}_{4}\right)_{3}\right]$ is given in this Supporting Information.

\section{Computational Study}

The DFT $+U$ calculations were performed with the the Quantum-ESPRESSO software. We applied our standard setup [Beridze, G.; Kowalski, P. M. Benchmarking the DFT plus U method for thermochemical calculations of uranium molecular compounds and solids. J. Phys. Chem. A 2014, 118 (50), 11797-11810] with PBEsol exchange-correlation functional [Perdew, J. P.; Ruzsinszky, A.; Csonka, G. I.; Vydrov, O. A.;Scuseria, G. E.; Constantin, L. A.; Zhou, X.; 
Burke, K. Restoring the Density-Gradient Expansion for Exchange in Solids and Surfaces. Phys. Rev. Lett. 2008, 100, 136406.], Vanderbilt pseudopotentials [Vanderbilt, D. Soft selfconsistent pseudopotentials in ageneralized eigenvalue formalism. Phys. Rev. B: Condens. Matter Mater. Phys. 1990, 41 (11), 7892-7895.] and plane-wave energy cutoff of 50 Ryd. PBEsol functional has been specifically selected as it by design results in good prediction of sturctural parameters, which is also the case of $\mathrm{Na}_{4}\left[\left(\mathrm{UO}_{2}\right)\left(\mathrm{SO}_{4}\right)_{3}\right.$ (Table S1 and S2). Based on previous studies we selected the Hubbard $U$ parameter of $3 \mathrm{eV}$, which is the value we computed with linear response method [Cococcioni, M.; de Gironcoli, S]. Linear response approach to the calculation of the effective interaction parameters in the LDA+U method. Phys. Rev. B: Condens. Matter Mater. Phys. 2005, 71 (3), 035105.] for U(VI) is various solid state compounds [Beridze, G.; Kowalski, P. M. Benchmarking the DFT plus U method for thermochemical calculations of uranium molecular compounds and solids. J. Phys. Chem. A 2014, 118 (50), 11797-11810; G. Beridze, A. Birnie, S. Koniski, Y. Ji and P. M. Kowalski, Prog. Nucl. Energy 92, 142v(2016).].

Table.S1. Lattice parameters of computed $\mathrm{Na}_{4}\left[\left(\mathrm{UO}_{2}\right)\left(\mathrm{SO}_{4}\right)_{3}\right]$ at $0 \mathrm{GPa}$

\begin{tabular}{|l|l|}
\hline & $\mathrm{Na}_{4}\left[\left(\mathrm{UO}_{2}\right)\left(\mathrm{SO}_{4}\right)_{3}\right]$ \\
\hline$a(\AA)$ & 5.225 \\
\hline$b(\AA)$ & 19.426 \\
\hline$c(\AA)$ & 11.228 \\
\hline$V\left(\AA^{3}\right)$ & 1139.65 \\
\hline
\end{tabular}




\section{Crystallographic Information:}

Table S2. Crystallographic data for $\mathrm{Na}_{4}\left[\left(\mathrm{UO}_{2}\right)\left(\mathrm{SO}_{4}\right)_{3}\right]$.

\begin{tabular}{|c|c|}
\hline Compound & $\mathrm{Na}_{4}\left[\left(\mathrm{UO}_{2}\right)\left(\mathrm{SO}_{4}\right)_{3}\right]$ \\
\hline Mass $\left(\mathrm{g} \mathrm{mol}^{-1}\right)$ & 650.17 \\
\hline Space group & C 2221 \\
\hline$a(\stackrel{\mathrm{A}}{)}$ & $5.2121(7)$ \\
\hline$b(\AA)$ & $19.448(3)$ \\
\hline$c(\stackrel{\AA}{)})$ & $11.1837(11)$ \\
\hline$V\left(\AA^{3}\right)$ & $1133.6(3)$ \\
\hline $\mathrm{Z}$ & 4 \\
\hline$\lambda(\AA)$ & 0.71073 \\
\hline$\rho_{\text {calcd }}\left(\mathrm{g} \mathrm{cm}^{-3}\right)$ & 3.809 \\
\hline$R(F)$ for $F_{\mathrm{o}}^{2}>2 \sigma\left(F_{\mathrm{o}}^{2}\right)^{a}$ & 0.0538 \\
\hline$w R_{2}\left(F_{\mathrm{o}}^{2}\right)^{b}$ & 0.1243 \\
\hline
\end{tabular}




\section{Topology Representations:}
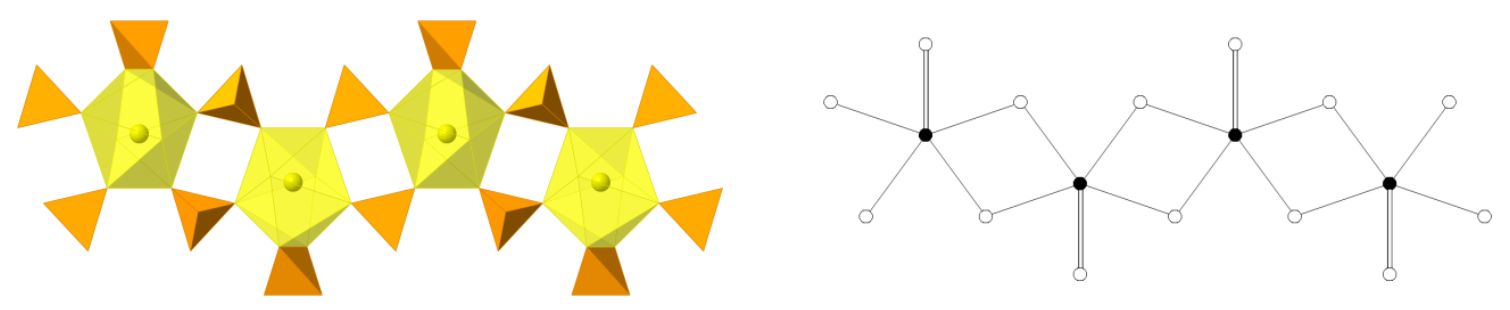

Figure S1. Topology depiction of one-dimensional chains found in $\mathrm{Na} 4\left[\left(\mathrm{UO}_{2}\right)\left(\mathrm{SO}_{4}\right)_{3}\right]$. The left shows the polyhedral representation and the left the topologic representation. The color scheme is identical to the one chosen in the article. For the topology, black nodes correspond to $\mathrm{UO}_{8}$ polyhedra and white nodes to sulfate tetrahedra. The double line shows edge-sharing, a single line corner-sharing.

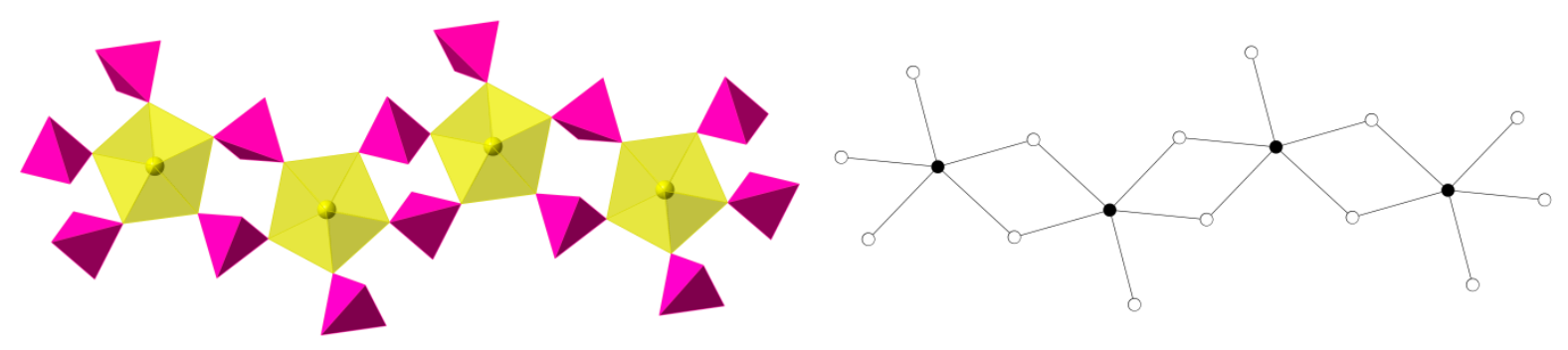

Figure S2. Topology depiction of one-dimensional chains found in $\mathrm{Na}_{4}\left[\left(\mathrm{UO}_{2}\right)\left(\mathrm{CrO}_{4}\right)_{3}\right]^{3}$. Same color scheme as applied above. 


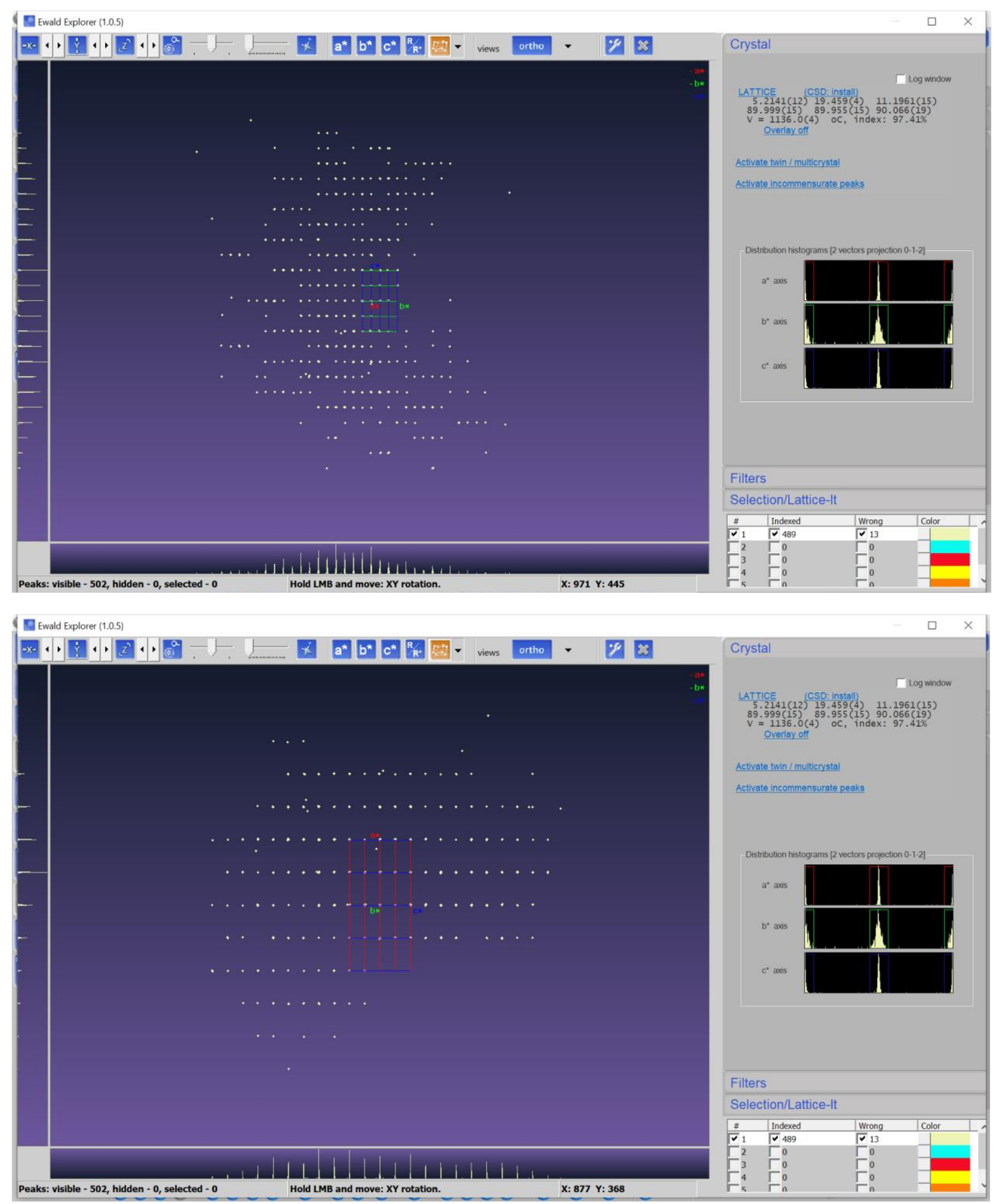



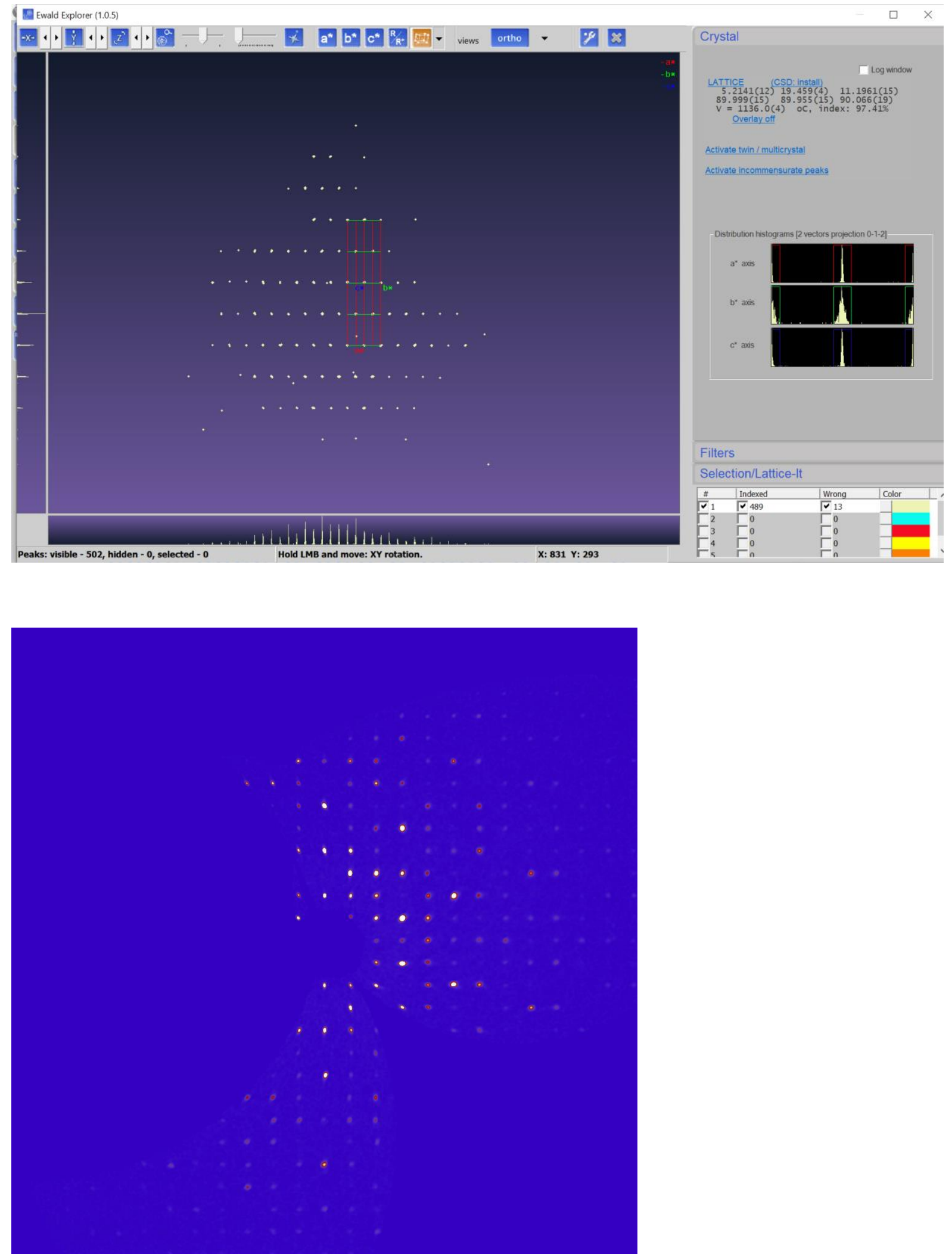

0KL 


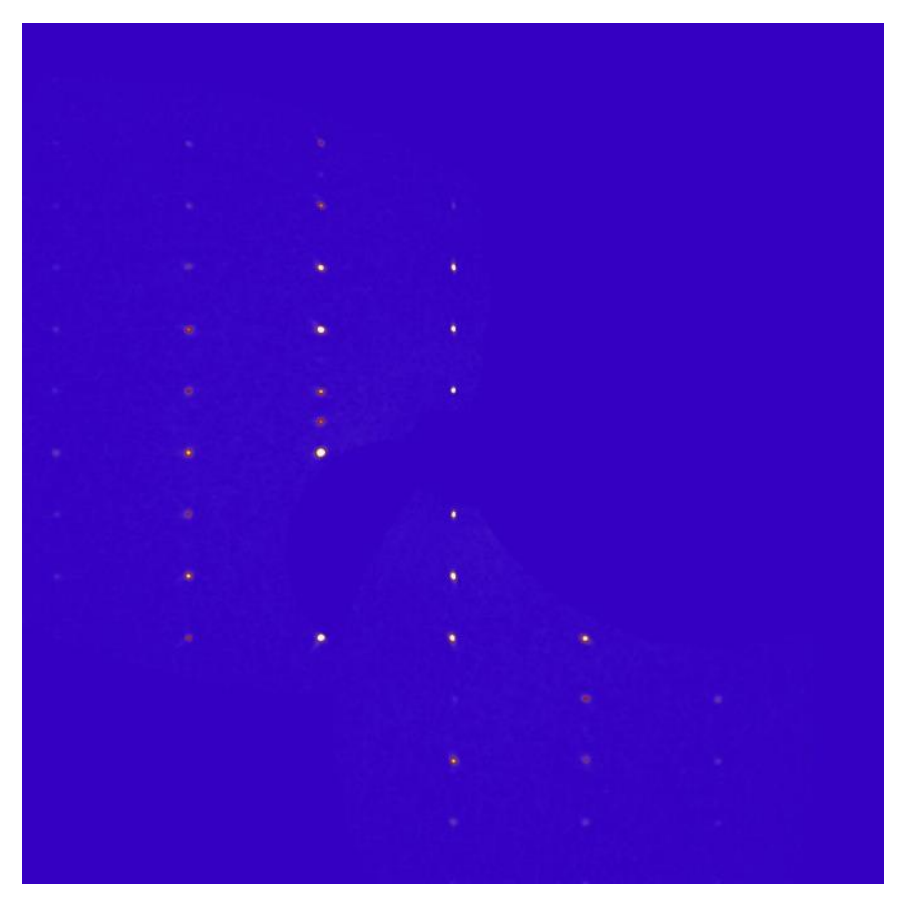

HOK

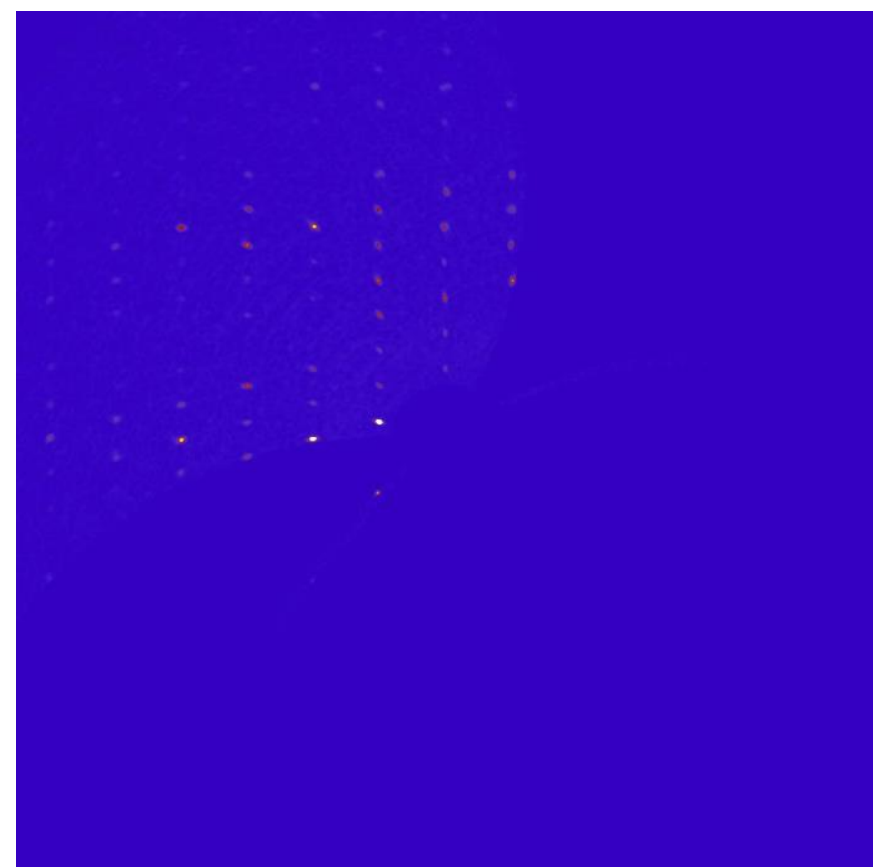

HKO

Figure S3. Reciprocal Space, Unite Cell choice and un wrapped precession-images for $\mathrm{Na}_{4}\left[\left(\mathrm{UO}_{2}\right)\left(\mathrm{SO}_{4}\right)_{3}\right]$ 


\section{BVS Analysis:}

Bond-valence sums (BVS) for all atomic positions were calculated. The bond-valence parameters for $\mathrm{S}^{\mathrm{VI}}-\mathrm{O}$, and $\mathrm{Na}^{\mathrm{I}}-\mathrm{O}$ are used according to Brese and $\mathrm{O}^{\prime} \mathrm{Keefee}^{4}$. The values for $\mathrm{UVI}^{\mathrm{V}} \mathrm{O}$ were taken from Burns et al. as $\mathrm{a}=2.051 \AA$ and $\mathrm{b}=0.519 \AA 5$.

\begin{tabular}{|c|c|c|c|c|c|}
\hline Atom & BVS [v.u.] & $\mathrm{CN}$ & $\mathbf{d}_{\min }[\AA \AA]$ & $d_{\text {avg }}[\AA \AA]$ & $\mathbf{d}_{\max }[\AA \AA]$ \\
\hline U1 & 6.120 & 8 & 1.764 & 2.306 & 2.627 \\
\hline S1 & 5.873 & 4 & 1.460 & 1.483 & 1.505 \\
\hline S2 & 5.830 & 4 & 1.457 & 1.485 & 1.517 \\
\hline $\mathrm{Na} 1$ & 0.941 & 8 & 2.459 & 2.606 & 2.741 \\
\hline $\mathrm{Na} 2$ & 1.310 & 8 & 2.305 & 2.493 & 2.663 \\
\hline $\mathrm{Na} 3$ & 0.901 & 7 & 2.348 & 2.598 & 2.894 \\
\hline
\end{tabular}

\begin{tabular}{cccccc}
\hline Atom & BVS [v.u.] & $\mathbf{C N}_{\text {tot }}$ & $\mathbf{C N}_{\mathbf{U}}$ & $\mathbf{C N}_{\mathbf{S}}$ & $\mathbf{C N}_{\mathbf{N a}}$ \\
\hline $\mathrm{O} 1$ & 1.943 & 4 & - & 1 & 3 \\
\hline $\mathrm{O} 2$ & 2.087 & 4 & 1 & 1 & 2 \\
\hline $\mathrm{O} 3$ & 1.995 & 2 & 1 & - & 1 \\
\hline $\mathrm{O} 4$ & 1.991 & 4 & - & 1 & 3 \\
\hline $\mathrm{O} 5$ & 1.935 & 3 & 1 & 1 & 1 \\
\hline $\mathrm{O} 6$ & 1.872 & 4 & - & 1 & 3 \\
\hline $\mathrm{O} 7$ & 2.030 & 4 & 1 & 1 & 2 \\
\hline
\end{tabular}




\section{References:}

1. Sheldrick, G. M., Crystal structure refinement with SHELXL. Acta Crystallographica Section C: Structural Chemistry 2015, 71 (1), 3-8.

2. Farrugia, L. J., WinGX and ORTEP for Windows: an update. Journal of Applied Crystallography 2012, 45 (4), 849-854.

3. Krivovichev, S. V.; Burns, P. C., The first sodium uranyl chromate, $\mathrm{Na} 4[(\mathrm{UO} 2)(\mathrm{CrO} 4) 3]$ : synthesis and crystal structure determination. Zeitschrift für anorganische und allgemeine Chemie 2003, 629 (11), 1965-1968.

4. Brese, N. E.; O'Keeffe, M., Bond-valence parameters for solids. Acta Crystallogr., Sect. B: Struct. Sci 1991, 47 (2), 192-197.

5. Burns, P. C.; Ewing, R. C.; Hawthorne, F. C., The Crystal Chemistry of Hexavalent Uranium: Polyhedron Geometries, Bond-Valence Parameters, and Polymerization of Polyhedra. Can. Mineral. 1997, 35, 1551-1570. 